Sādhanā Vol. 27, Part 3, June 2002, pp. 383-392. @ Printed in India

\title{
Laser power coupling efficiency in conduction and keyhole welding of austenitic stainless steel
}

\author{
A K NATH, R SRIDHAR, P GANESH and R KAUL \\ Industrial $\mathrm{CO}_{2}$ Laser Section, Centre for Advanced Technology, Indore 452 013, \\ India \\ e-mail: aknath@cat.ernet.in
}

MS received 24 May 2001; revised 28 December 2001

\begin{abstract}
Laser welding of thin sheets of AISI 304 stainless steel was carried out with high power $\mathrm{CW} \mathrm{CO}_{2}$ laser. The laser power utilized in the welding process was estimated using the experimental results and the dimensionless parameter model for laser welding; and also the energy balance equation model. Variation of laser welding efficiency with welding speed and mode of welding was studied. Welding efficiency was high for high-speed conduction welding of thin sheets and also in keyhole welding process at high laser powers. Effect of pre-oxidization of the surface and powder as filler material on laser power coupling is also reported. The paper also discusses effect of microstructure on the cracking susceptibility of laser welds.
\end{abstract}

Keywords. Laser welding; coupling efficiency; conduction loss, austenitic stainless steel; keyhole welding; solidification cracking.

\section{Introduction}

Laser welding of thin sheet at high speeds is one of the attractive applications of high power lasers. Good quality weld of thin stainless steel sheets at welding speeds in $20-50 \mathrm{~m} / \mathrm{min}$ range with high power lasers have been demonstrated. Metal being opaque and highly reflecting to the laser radiation, most of the laser power is reflected away and a small fraction is absorbed within a very small depth near the surface. Surface temperature rises and heating along the thickness of the sheet occurs via heat conduction process. Reflectivity of the polished stainless steel surface is about $98 \%$ at the room temperature and it reduces as the temperature of the surface rises. In laser welding of relatively thicker sheets at high laser power densities a keyhole is formed and it is sustained by the escaping vapour. Laser beam penetrates through the keyhole along the thickness of the sheet and produces deep-penetration weld. One of the concerns in laser welding is the coupling efficiency of laser power in the metal sheet. In order to estimate the coupling efficiency and determine various laser and process parameters for good quality welding we carried out bead-on welding of AISI 304 stainless steel sheets of various thickness in $0.1-1.55 \mathrm{~mm}$ range in both conduction and keyhole welding modes. Estimated laser coupling efficiencies in conduction and keyhole welding were about $16 \%$ and $65 \%$ respectively.

A list of symbols is given at the end of the paper 


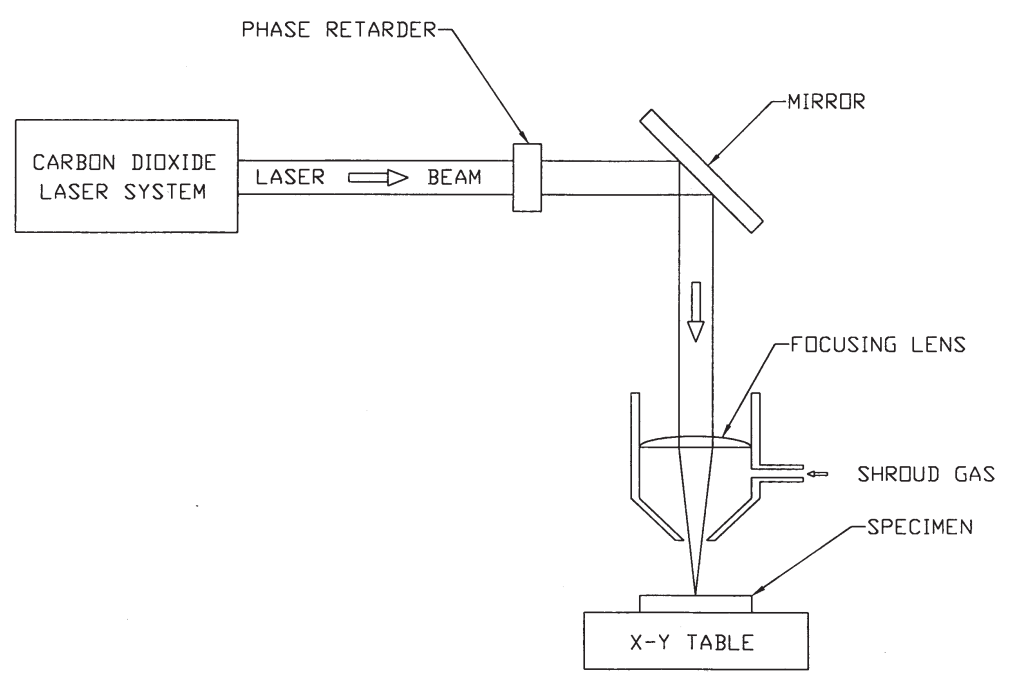

Figure 1. Laser welding set-up (schematic).

\section{Experiment}

The experimental setup, schematically shown in figure 1, consists of an indigenously developed transverse flow $\mathrm{CW} \mathrm{CO}_{2}$ laser integrated with a laser beam delivery system and a computer controlled $x-y$ coordinate table. The laser can give $3.5 \mathrm{~kW}$ maximum power in a multimode beam and about $2 \mathrm{~kW}$ in the $\mathrm{TEM}_{01 *}$ mode when it is incorporated with an intra-cavity aperture of suitable diameter. The beam that comes out of the laser is plane polarized. The laser beam delivery system consists of a phase-retarder to convert the plane polarized laser beam to a circularly polarized beam, a beam bender and a zinc-selenide focusing lens to focus the laser beam on the sheet. At the end of the beam delivery system a nozzle is incorporated through which focussed beam comes out. A shrouding gas is also flown through the nozzle along with the laser beam. In the present experiment argon was used as shrouding gas at about 20-liters/minute flow rate. The focal length of the lens is $100 \mathrm{~mm}$ and the spot size of the focussed laser beam at the metal sheet surface is about 300 micron. Laser welding of AISI 304 stainless steel sheets of different thickness in the range of $0.1-1.55 \mathrm{~mm}$ was carried out at various laser power and speeds. The optimum laser power and weld-speed for good quality weld of different sheet thickness are tabulated in table 1 . Conduction welding of $0.1 \mathrm{~mm}$ thick

Table 1. Estimation of coupling efficiency.

Laser spot size at the surface $=\sim 300$ micron

\begin{tabular}{lcccccccc}
\hline No.* & $\begin{array}{c}\text { Sheet } \\
\text { thickness } \\
(\mathrm{mm})\end{array}$ & $\begin{array}{c}\text { Laser } \\
\text { power } \\
\text { (watts) }\end{array}$ & $\begin{array}{c}\text { Welding } \\
\text { speed } \\
(\mathrm{m} / \mathrm{s})\end{array}$ & $\begin{array}{c}\text { Weld } \\
\text { width } \\
(\mathrm{mm})\end{array}$ & $Y$ & $X$ & $\begin{array}{c}\text { Laser power } \\
\text { absorbed } \\
\text { (watts) }\end{array}$ & $\begin{array}{c}\text { Coupling } \\
\text { efficiency } \\
(\%)\end{array}$ \\
\hline 1 & 0.1 & 1200 & 0.33 & 0.4 & 7.5 & 15.6 & 175 & 15 \\
2 & 0.5 & 1700 & 0.04 & 0.85 & 1.5 & 4.5 & 260 & 15.4 \\
3 & 1.2 & 2250 & 0.008 & 1.0 & 0.38 & 2.55 & 370 & 16.6 \\
4 & 1.0 & 1800 & 0.008 & 1.0 & 0.38 & 2.55 & 300 & 16.6 \\
5 & 1.55 & 2250 & 0.05 & 1.3 & 2.7 & 8.0 & 1450 & 65 \\
\hline
\end{tabular}

*Nos. 1-4 are for conduction welding while 5 is for keyhole welding 
sheet was achieved with $1200 \mathrm{~W}$ laser-power at welding-speeds up to $20 \mathrm{~m} / \mathrm{min}$, limited by the capacity of the CNC $x-y$ table. Keyhole welding of $1.55 \mathrm{~mm}$ thick sheet was performed with $2250 \mathrm{~W}$ laser power at $3 \mathrm{~m} / \mathrm{min}$ weld-speed. Photomicrographs of the weld-beads and their cross-sections are presented in figures 2-4. Results of metallographic examination of laser welded specimens are discussed in $\S 4$.

(a)

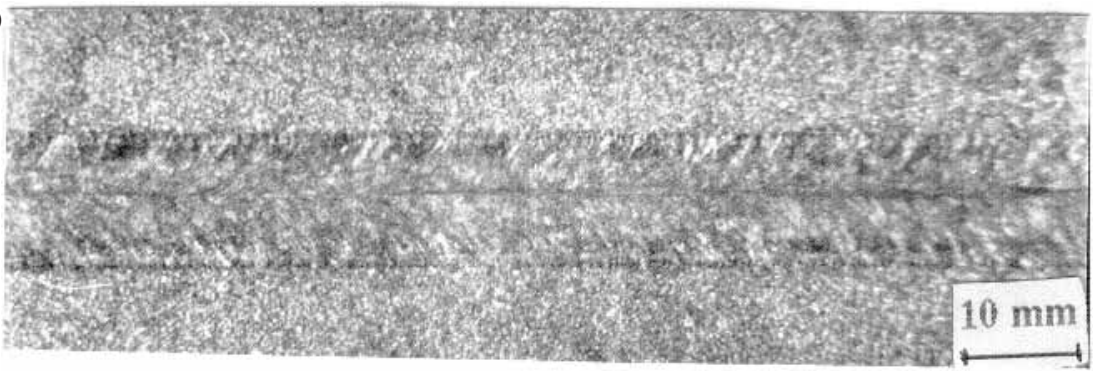

(b)
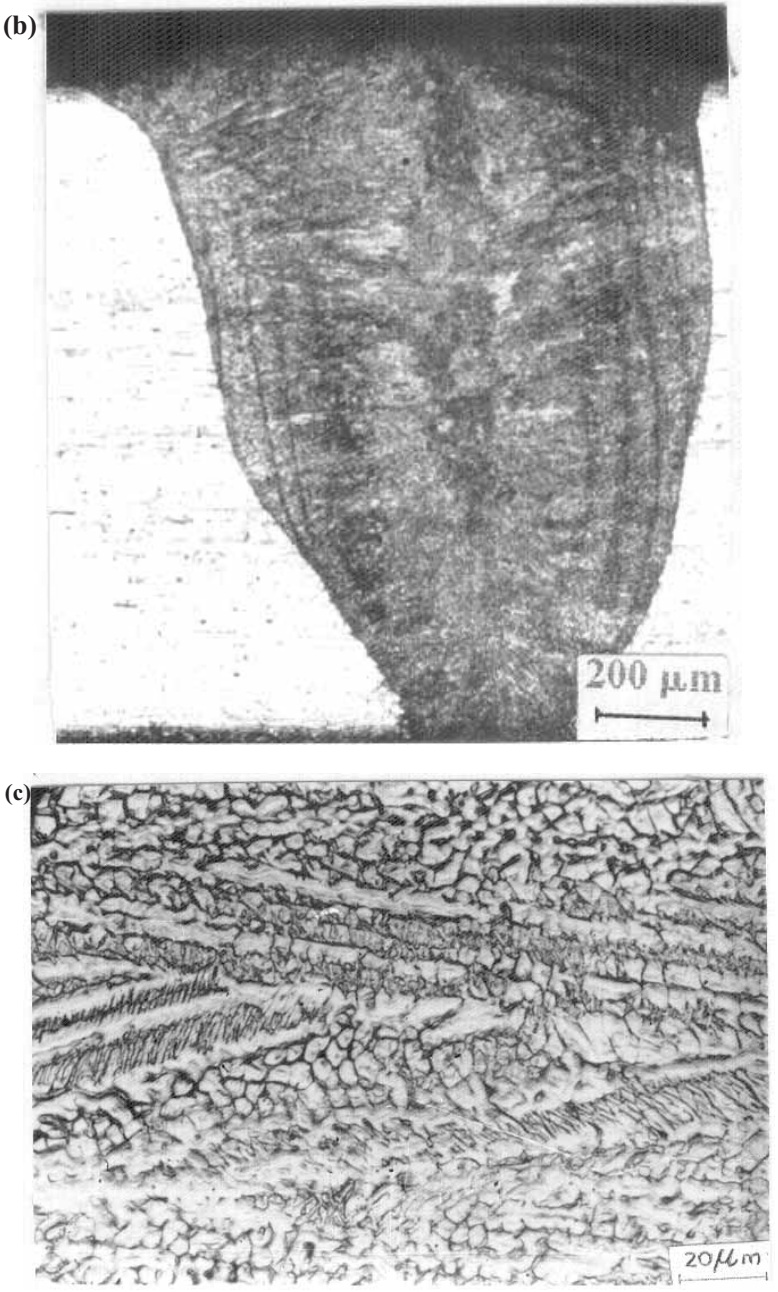

Figure 2. Laser weld of $1.2 \mathrm{~mm}$ thick AISI 304 stainless steel sheet. (a) Photomacrograph showing grain orientation of the fusion zone. (b) Transverse crosssection of the weldment. (c) Primary ferritic mode of solidification of the fusion zone. 
(a)
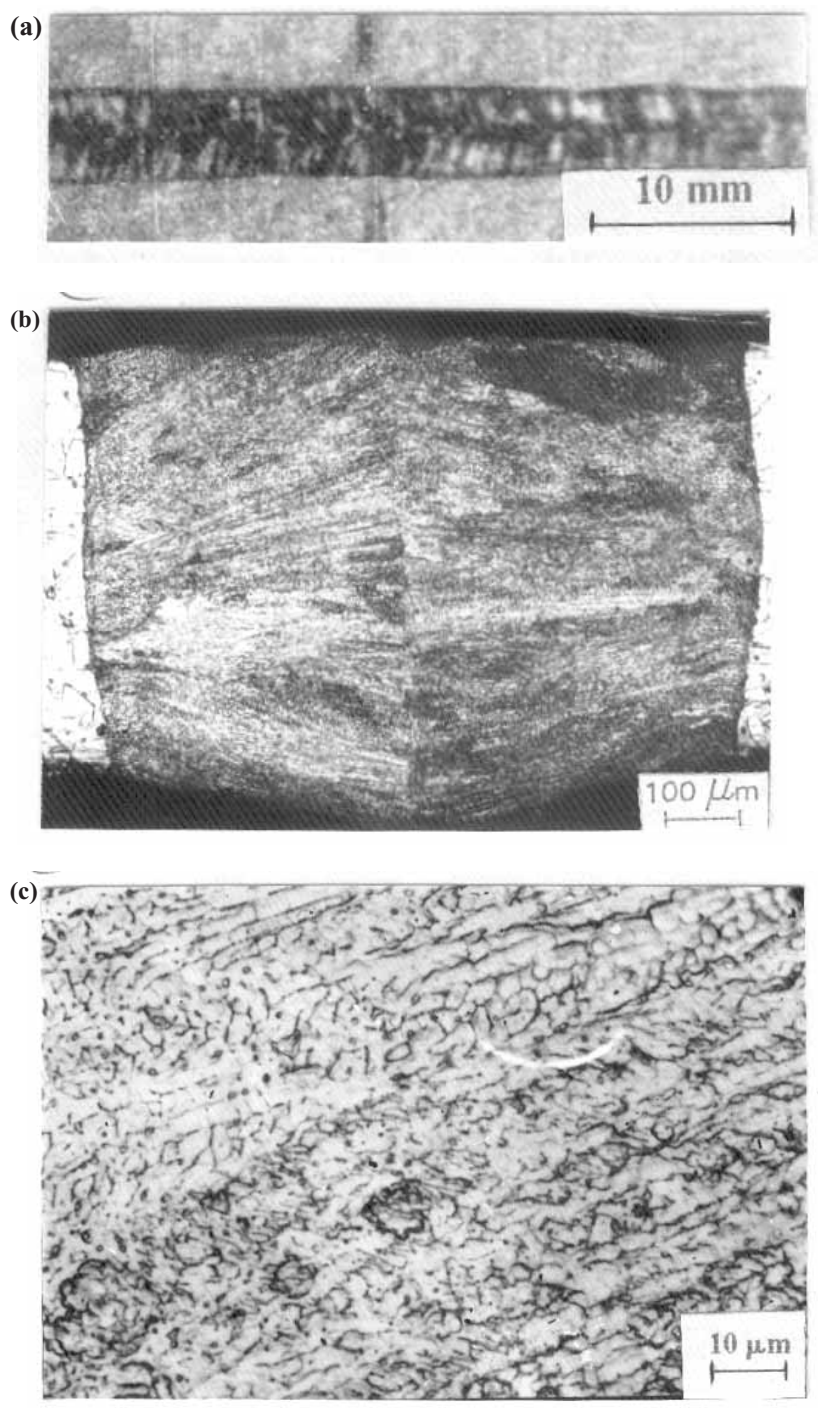

Figure 3. Laser weld of 0.5 mm thick AISI 304 stainless steel sheet. (a) Photomacrograph showing steep columnar grains of the fusion zone meeting at the weld centeline. (b) Transverse cross-section of the laser weldment. (c) Localized zone of primary ferritic mode of solidification in the pre-dominantly primary austenite solidified fusion zone.

\section{Estimation of laser power coupling efficiency}

In order to estimate the laser power coupling efficiency we used the dimensionless parameter model for laser welding, which has proven valuable in characterizing laser welding (Steen 1998). The two dimensionless parameters are the normalized speed and the normalized power, defined as follows:

$$
\text { normalized speed, } Y=v . w / \alpha \text { and normalized power, } X=P / t . K . T_{m},
$$

where $v$ is the welding speed, $w$ is the weld width, $P$ is the laser power absorbed by metal, $t$ is the sheet thickness, and $\alpha, K$ and $T_{m}$ are the thermal diffusivity, thermal conductivity and melting temperature of the metal, respectively.

At high welding speed the relation between these two parameters can be given as (Steen 1998): 


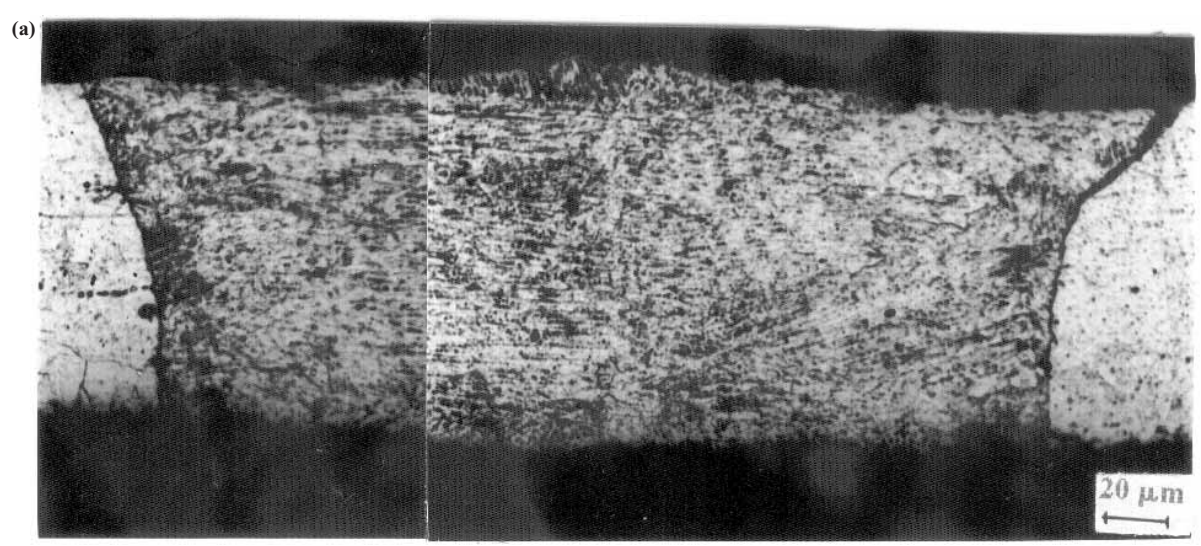

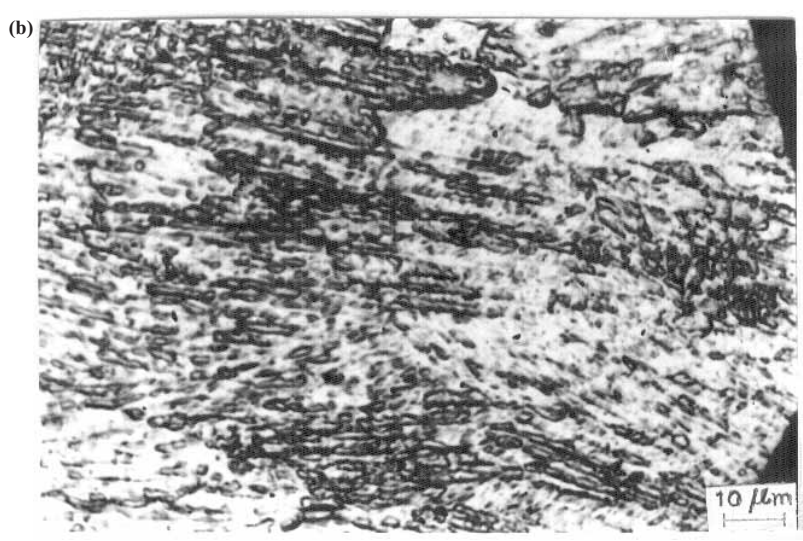

$$
Y=0.483 X,
$$

while at low processing speeds it can be expressed as

$$
6.3 / X=\ln (4.5 / Y) .
$$

Using the typical values of the thermo-physical properties (Steen 1998) of stainless steel in the above equations, the laser power absorbed in the metal was estimated for different welding conditions. Typical values are density $=8030 \mathrm{~kg} / \mathrm{m}^{3}$, latent heat of fusion $=300 \mathrm{~kJ} / \mathrm{kg}$, latent heat of vaporization $=6500 \mathrm{~kJ} / \mathrm{kg}$, specific heat $=500 \mathrm{~J} / \mathrm{kg} .{ }^{\circ} \mathrm{C}$, melting temperature $=$ $1450{ }^{\circ} \mathrm{C}$, vaporization temperature $=3000{ }^{\circ} \mathrm{C}$ and thermal conductivity $=20 \mathrm{~W} / \mathrm{m}^{\circ} \mathrm{C}$. The average value of weld width was measured from the optical photomicrographs of the weld cross-section. The results along with processing parameters are presented in table 1 .

The laser power coupling efficiency in conduction welding is about $15-17 \%$ which is very close to the percentage absorption (14\%) by stainless steel reported at the melting temperature (Xie \& Kar 1997). However, in keyhole welding the laser power coupling is quite high, about $65 \%$. This is because the laser beam undergoes multiple reflection and absorption in the keyhole.

We calculated the amount of laser power lost through conduction using the energy balance equation. Neglecting the radiative and convective power losses, which are usually very small, 
the laser power absorbed can be equated as the following:

$$
P=\rho . w . t . v\left[C_{p}\left(T_{a}-T_{o}\right)+L_{m}\right]+P_{c o n},
$$

where $\rho, C_{p}$ and $L_{m}$ are the density, specific heat and latent heat of fusion of the metal respectively, $T_{o}$ is the ambient temperature, and $T_{a}$ is the temperature to which molten metal is heated.

We can assume that the heat is conducted away from three sides of the full-penetrationweld, as the laser beam moves forward. Heat conducted away from the trailing edge can be neglected. Temperature along the thickness in full-penetration weld can be assumed to be the same, therefore there is no heat conduction along the thickness of the sheet, and heat conduction loss is independent of thickness. Under this assumption the conduction loss $P_{\text {con }}$ can be determined with the Fourier law of heat conduction as

$$
P_{c o n}=\{-w . t . K \mathrm{~d} T / \mathrm{d} x-2 v \cdot \tau . t . K \mathrm{~d} T / \mathrm{d} y\},
$$

where $\tau=l / v$, is the dwell-time of the beam in travelling across its diameter, $l$. The laser beam moves in the $x-y$ plane along the $\mathrm{x}$-axis.

It can be assumed that the temperature drops from melting temperature $T_{m}$ to almost ambient temperature beyond the diffusion length, $2(\alpha \cdot \tau)^{1 / 2}$ Under this assumption we can write

$$
\mathrm{d} T / \mathrm{d} x=\mathrm{d} T / \mathrm{d} y=-\left(T_{m}-T_{o}\right) / 2(\alpha \cdot \tau)^{1 / 2} .
$$

Using (3)-(5), the total laser absorbed, conduction power loss and power utilized in melting are calculated for the welding parameters mentioned in table 1 . These are tabulated in table 2.

It is seen from these calculations that the conduction loss is very low at very high welding speed and is relatively high for slower welding speeds in conduction mode welding. In keyhole welding also the conduction loss is relatively low.

In order to improve laser power coupling in conduction welding different methods such as pre-oxidization of the surface and powder as filler material have been suggested (Xie \& Kar 1997). With this consideration we carried out conduction mode welding in different ways, viz. pre-oxidation of metal surface by laser heating in air, chemical passivation, etching of the surface and with pre-placed stainless steel powder as filler material. Results of relative values of laser power absorption are presented in table 3 .

It was found that absorption of laser power could be enhanced by about $30 \%$ with either pre-oxidation of surface or chemical passivation, and by about $50 \%$ with suitable powder placed on the surface.

Table 2. Conduction loss calculations.

\begin{tabular}{ccccccc}
\hline No. & $\begin{array}{c}\text { Sheet } \\
\text { thickness } \\
(\mathrm{mm})\end{array}$ & $\begin{array}{c}\text { Welding } \\
\text { speed } \\
(\mathrm{m} / \mathrm{s})\end{array}$ & $\begin{array}{c}\text { Laser power } \\
\text { absorbed } \\
\text { (watts) }\end{array}$ & $\begin{array}{c}\text { Laser power } \\
\text { for melting } \\
\text { (watts) }\end{array}$ & $\begin{array}{c}\text { Conduction } \\
\text { loss } \\
\text { (watts) }\end{array}$ & $\begin{array}{c}\text { Conduction } \\
\text { loss } \\
(\%)\end{array}$ \\
\hline 1 & 0.1 & 0.33 & 202 & 198 & 4 & 2 \\
2 & 0.5 & 0.04 & 325 & 217 & 108 & 33 \\
3 & 1.25 & 0.008 & 250 & 140 & 110 & 44 \\
4 & 1.0 & 0.008 & 225 & 135 & 90 & 40 \\
5 & 1.55 & 0.05 & 1600 & 1190 & 410 & 25 \\
\hline
\end{tabular}


Table 3. Effect of pre-oxidation and powder layer on laser power absorption (laser power $=2 \mathrm{~kW}$ ).

\begin{tabular}{lll}
\hline No. & \multicolumn{1}{c}{ Surface condition } & Relative absorption \\
\hline 1 & Bare surface & 1 \\
2 & Surface oxidized by laser scanning in air & 1.35 \\
3 & Chemically passivated surface & 1.3 \\
4 & Chemically etched surface & 1.05 \\
5 & Pre-placed stainless steel powder & $1.5^{*}$ \\
\hline
\end{tabular}

*This included power utilized in melting the powder placed on the surface

\section{Metallographic examination}

\subsection{Results}

Laser welded AISI 304 stainless steel sheet specimens were examined under stereo microscope as well as under optical microscope. Important features brought out by metallographic examination are as follows:

4.1a Sheet of $1.2 \mathrm{~mm}$ thickness: Laser welds were associated with inclined columnar grains (at about $45^{\circ}$ from the centreline) growing from the opposite sides of the weld pool and a thin region of axial grains at the weld centreline (appear as fine equiaxed grains on the transverse cross-section), as shown in figures $2 \mathrm{a}-\mathrm{b}$. The fusion zone of these welds exhibited microstructure consisting of vermicular and lathy ferrite, representing primary ferrite mode of solidification. Figure $2 \mathrm{c}$ presents microstructure of the fusion zone of one of these welds. Primary ferrite solidified austenitic stainless steel welds are considered to be more resistant against solidification cracking than those associated with primary austenitic mode of solidification.

4.1b Sheets of $0.5 \mathrm{~mm}$ thickness: Laser welds of 0.5 - $\mathrm{mm}$ thick sheets exhibited steep angles of abutment between columnar grains growing from the opposite sides of the weld pool at the weld centreline, as shown in figures $3 \mathrm{a}$ and $\mathrm{b}$. There was no sign of axial grains at the weld centreline. These welds were largely associated with primary austenite mode of solidification. However, a few zones of primary ferrite mode of solidification were also noticed in the fusion zones, figure $3 \mathrm{c}$. One of the laser welds was found to be associated with a centerline solidification crack, as shown in figure 5 .

4.1c Sheets of $0.1 \mathrm{~mm}$ thickness Like $0.5 \mathrm{~mm}$ thick laser welds, laser welds of $0.1 \mathrm{~mm}$ thick sheets were also found to be associated with steep angle of abutment between columnar grains at weld centreline, figure $4 \mathrm{a}$. The welds were associated with primary austenitic mode of solidification, as shown in figure $4 \mathrm{~b}$. A small localized region of burn through was also noticed in one of these laser weld samples, figure 6 . The cause of this defect is attributed to the transient fluctuation in laser power, which have effected localized burn through in $0.1 \mathrm{~mm}$ thick sheet.

\subsection{Discussion}

Solidification cracking is one of the important problems encountered during welding of austenitic stainless steel. It involves formation of low melting point eutectic phase at the grain 


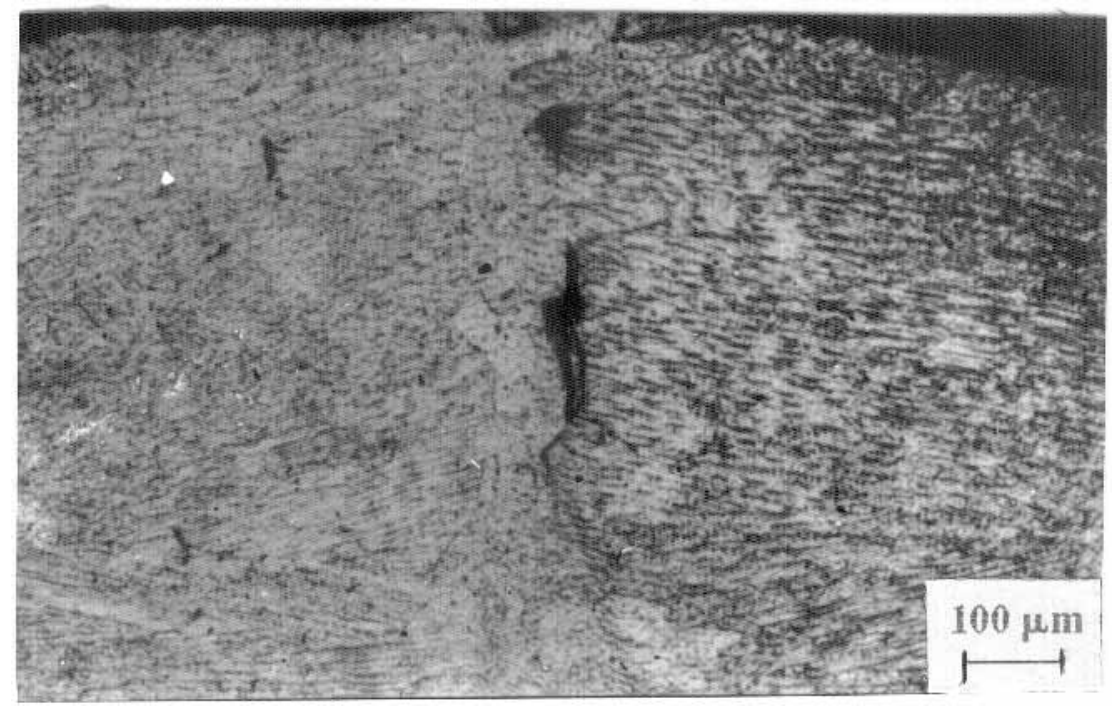

Figure 5. A centreline crack in the fusion zone of one of the laser welds of 0.5 thick AISI 304 stainless steel sheet.

boundaries of solidifying weld metal which leads to intergranular cracking under the influence of welding induced shrinkage stresses (Sindo 1987, pp 220-221). It has been found that the cracking can be avoided by selecting compositions that solidify in the ferritic mode or by reducing the concentration of impurity elements (e.g. P and S) to very low levels (Dixon 1989). Lippold (1994) found that under rapid solidification conditions encountered during pulsed laser welding, weld solidification suffers a shift towards the austenite side, which significantly influences cracking. Vitek \& David (1982, 1983) also noted that the high cooling rate associated with laser welding significantly altered the weld solidification structure.

The results of metallographic examination do show that defect free welds with crack resistant microstructure can be produced in $1.2 \mathrm{~mm}$ thick sheet of AISI 304 stainless steel, which

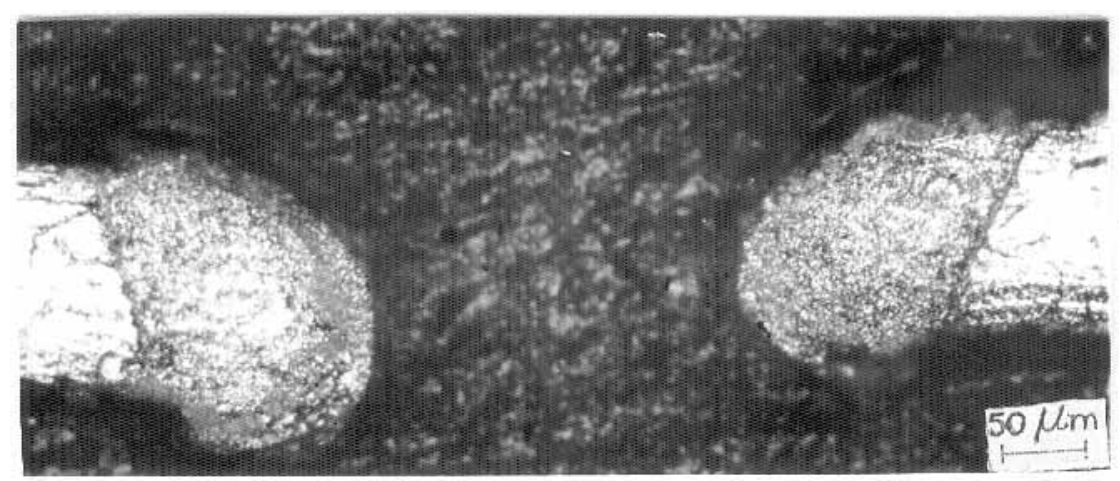

Figure 6. Photomicrograph showing a localized region of burn through in one of the laser welds of $0.1 \mathrm{~mm}$ thick stainless steel sheet. 
was welded at about $0.5 \mathrm{~m} / \mathrm{min}$ weld speed. However, in thinner sheets of $0.5 \mathrm{~mm}$ and 0.1 $\mathrm{mm}$, which were welded at relatively high speeds of about $2.4 \mathrm{~m} / \mathrm{min}$ and $20 \mathrm{~m} / \mathrm{min} \mathrm{respec-}$ tively, the weldments were associated with steep angle of abutment between columnar grains at weld centreline. This kind of microstructure arises from tear-drop shaped weld pool due to increased weld speed and gives rise to continuous liquid film of low melting point, which tends to segregate at the weld centerline, thereby making these welds susceptible to centerline solidification cracking. Use of grain refinement techniques like electromagnetic stirring, micro-cooler inoculation and ultrasonic vibration may prove useful in improving solidification cracking resistance of these welds (Simpson 1977; Masuda et al 1986; Sindo 1987, pp 156-163; Hallum \& Baeslack 1990).

\section{Conclusions}

In the light of the results of the present study, the following conclusions are drawn.

- Good quality laser welds can be obtained in AISI 304 stainless steel sheets. However, at relatively high welding speeds fusion zone develops steeply oriented columnar grains meeting head-on at the weld centreline, making resultant weld susceptible to centreline solidification cracking.

- Absorption of $\mathrm{CO}_{2}$ laser beam in conduction welding and keyhole welding is about $15 \%$ and $65 \%$ respectively.

- Conduction loss is small at high welding speeds and in keyhole welding.

- Pre-oxidation of surface and stainless steel powder coating can improve absorption by about $30-50 \%$.

We thank L B S Rana and C H Prem Singh for technical assistance.

\section{List of symbols}

$C_{p} \quad$ specific heat;

$K$ thermal conductivity;

$L_{m} \quad$ latent heat of fusion;

$P \quad$ laser power absorbed;

$P_{\text {con }} \quad$ conduction loss;

$T_{m} \quad$ melting temperature of the metal;

$T_{a} \quad$ temperature to which molten metal is heated;

$T_{0} \quad$ ambient temerature;

$t \quad$ sheet thickness;

$v \quad$ welding speed;

$w \quad$ weld width;

$Y \quad$ normalized speed;

$X \quad$ normalized power;

$\alpha \quad$ thermal diffusivity;

$\rho$ density;

$\tau \quad$ dwell time of the laser beam in travelling across its diameter. 


\section{References}

Dixon B F 1989 Control of magnetic permeability and solidification cracking in welded nonmagnetic steel. Welding J. 68(5): 171s-180s

Hallum D L, Baeslack W A 1990 Nature of grain refinement in titanium alloy welds by microcooler inoculation. Welding J. 69(9): 326s-336s

Lippold J C 1994 Solidification behavior and cracking susceptibility of pulsed laser welds in austenitic stainless steel welds. Welding J. 73(6): 129s-139s

Matsuda F, Nakata K, Sano N 1986 Effect of electromagnetic stirring on weld solidification structure of austenitic stainless steel. Trans. of JWRI 15(2): 155-166

Simpson R P 1977 Controlled weld pool solidification structure and resultant properties of yttrium inoculation of Ti-6Al-6V-2Sn weld. Welding J. 56(3): 67s-77s

Sindo K 1987 Welding metallurgy (New York: John Wiley \& Sons)

Steen W M 1998 Laser material processing 2nd edn (London: Springer) p. 206

Vitek J M, David S A 1982 Trends in welding research in the United States (ed.) S A David (Materials Park, OH: Am. Soc. Metals)

Vitek J M, David S A 1983 Metall. Trans. A14: 1833-1843

Xie J, Kar A 1997 Laser welding of cold-rolled steel sheets. Proc. Laser Mater. Process. Conf., ICALEO 97 (eds.) R Fabbro, A Kar, A Matsunawa (Orlando, FL: Laser Inst. Am.) pp G164-170 